\title{
Current pediatric cancer survivorship practices: a report from the Children's Oncology Group
}

\author{
K. E. Effinger ${ }^{1,2} \cdot$ R. Haardörfer ${ }^{3} \cdot$ J. Gilleland Marchak ${ }^{1,2} \cdot$ C. Escoffery ${ }^{3} \cdot$ W. Landier ${ }^{4} \cdot$ A. Kommajosula ${ }^{3}$. \\ E. Hendershot ${ }^{5} \cdot$ K. T. Sadak ${ }^{6}$ D. Eshelman-Kent ${ }^{7} \cdot$ K. Kinahan ${ }^{8}$ - D. R. Freyer ${ }^{9}$ E. J. Chow ${ }^{10} \cdot$ A. C. Mertens ${ }^{1,2}$
}

Received: 18 November 2021 / Accepted: 16 December 2021

(c) The Author(s), under exclusive licence to Springer Science+Business Media, LLC, part of Springer Nature 2021

\begin{abstract}
Purpose The purpose of this study is to describe current survivor services provided by COG institutions.

Methods A 190-question online survey was distributed to 209 COG member institutions over a 5-month period in 2017. Descriptive statistics were used to describe survivor services and explore their changes between 2007 and 2017.

Results Representatives from 153 (73\%) institutions completed the survey. Of these, $96 \%$ of institutions reported that they provide pediatric cancer survivor care either in a specialized late effects program (75\%) or a regular pediatric oncology clinic (24\%). However, only $29.8 \%$ of institutions reported that $>75 \%$ of eligible patients were seen in a survivorship clinic. The most prevalent reported barriers to survivor care were lack of dedicated time (58\%) and lack of funding for program development (41\%). In 2017, 88\% of institutions provided a treatment summary compared to $31 \%$ in 2007.

Conclusion The majority of COG institutions have dedicated care for pediatric and young adult survivors of childhood cancer; however, at most institutions, $<75 \%$ of eligible patients access this care. Research into more efficient technology strategies is needed to ensure all survivors the opportunity to receive appropriate follow-up care.

Implications for Cancer Survivors This survey provides a snapshot of the status of late effects services within COG institutions and provides information on residual gaps in services. Next steps should focus on the importance of attendance in a survivorship clinic on the physical health and psychosocial outcomes in cancer survivors.
\end{abstract}

Keywords Pediatric cancer $\cdot$ Survivorship $\cdot$ Late effects services $\cdot$ Cross-sectional study

\section{Introduction}

Currently, the 5-year overall survival rate for childhood and adolescent cancer is $>85 \%$, which translates to $>480,000$ survivors of childhood cancer living in the USA [1]. These survivors have an increased risk of chronic health conditions,

\section{A. C. Mertens}

amerten@emory.edu

Emory University School of Medicine, Atlanta, USA

2 Aflac Cancer and Blood Disorders Center, Children's Healthcare of Atlanta, Atlanta, USA

3 Rollins School of Public Health, Emory University, Atlanta, USA

4 University of Alabama at Birmingham School of Medicine, Birmingham, USA

5 McMaster Children's Hospital, Hamilton Health Sciences, Hamilton, Canada or late effects, due to their cancer and its treatment $[2,3]$. With the growing number of survivors and increasing awareness of late effects, cancer survivorship has become a national public health priority in the USA. Long-term survivor care is especially important for survivors of pediatric cancers, as their risk for morbidity and mortality increases

6 University of Minnesota Masonic Children's Hospital and Cancer Center, Minneapolis, USA

7 Cincinnati Children's Hospital, Cincinnati, USA

8 Robert H. Lurie Comprehensive Cancer Center of Northwestern University, Chicago, USA

9 Cancer and Blood Disease Institute, Children's Hospital Los Angeles, Los Angeles, USA

10 Fred Hutchinson Cancer Research Center, Seattle Children's Hospital, Seattle, USA 
with aging $[4,5]$. The purpose of long-term follow-up care is to provide survivors with individualized surveillance and treatment for late effects of cancer therapy to decrease morbidity and mortality and increase quality of life after pediatric cancer.

To aid in the appropriate surveillance of pediatric cancer survivors, the Children's Oncology Group (COG) developed the Long-Term Follow-Up Guidelines for Survivors of Childhood, Adolescent and Young Adult Cancers (LTFU Guidelines) [6, 7]. These risk-based, exposure-related clinical practice guidelines provide recommendations for screening and management of late effects in survivors. The LTFU Guidelines are intended for use beginning 2 or more years following the completion of cancer therapy in order to standardize and enhance follow-up care provided to survivors of pediatric cancer throughout their lifespan.

In 2003, the Institute of Medicine recommended that pediatric oncology begin the process of examining and evaluating services for survivors [8]. This recommendation was addressed by members of the COG Nursing, Adolescent and Young Adult, and Survivorship Committees when they distributed a survey to COG member institutions in 2007 [9]. Findings from this survey described survivorship services and models of care in use for survivors of pediatric and adolescent cancer. Results from this survey demonstrated that of the COG institutions who responded, $87 \%$ reported providing some type of survivor care, but only $59 \%$ provided dedicated survivorship care, and only $31 \%$ provided detailed survivorship care plans. These findings significantly contributed to the understanding of survivorship services throughout COG and served as a resource for metrics on improving survivor programs moving forward. In addition, since approximately $90 \%$ of childhood/adolescent cancer patients are seen at COG institutions in North America, this survey of COG institutions essentially represents the standard of clinical care at pediatric oncology treatment centers in North America [10].

Due to emerging research over the past decade regarding models of care for survivors, now is an opportune time to re-evaluate COG institutions' late effects services. The primary objectives of this analysis were to determine the status of cancer survivorship offered at COG institutions and to evaluate the changes in survivorship care at these institutions over a 10 -year time period.

\section{Methods}

Methodology for this cross-sectional survey was similar to the study conducted by Eshelman-Kent et al. in 2007, to maximize comparability between surveys [9]. The online survey was made available from October 2017 to February 2018 on SurveyMonkey, a HIPAA-compliant software designed for electronic data collection. The Emory Institutional Review Board (IRB) deemed this study exempt from IRB review.

\section{Sample}

COG emailed a survey introduction and instructions to the contact person listed in the COG Late Effects Directory of Services at each member institution $(n=209)$. If unknown or the contact person had changed, the request went to the designated COG Principal Investigators (PIs) with a request to complete or designate/forward the subsequent request to the appropriate contact. Following the introductory email, Emory University researchers sent an email including a link to complete the confidential online survey (further described below). Two additional email notifications were sent at approximately 2 weeks and 1-month later. Finally, co-authors contacted all non-responding institutions in order to solicit their participation. After these efforts, for remaining non-responding COG institutions, a brief 3-item survey was emailed to COG PIs at these institutions, to ascertain if each institution provided late effects care for childhood cancer survivors.

\section{Measures}

The primary survey consisted of 190 -items that assessed cancer survivorship practices, services, and delivery at COG institutions. (The survey is available upon request to authors.) It included questions on patient eligibility for late effects services, models of care, clinic volume, clinic services available, resources, and perceived barriers to services. Respondents were allowed to omit responses to individual questions at their discretion. To assess changes in survivorship services over time, a subset of questions from the 2007 survey were re-asked on the 2017 survey [9]. Institutional name and locations were reviewed, and institutional responses were compared.

\section{Analysis}

Returned 2017 surveys were reviewed to make sure there was only one response per institution. The 2017 survey data were included if the first 10 questions of the survey, consisting of institutional demographic information and whether the institution provides late effects care for childhood cancer survivors, were completed. If respondents reported "no" to providing late effects care, they exited the remainder of the survey. The amount of missing data for each question was minimal and varied slightly depending on the query. The data from both the 2007 and 2017 survey were merged based on the clinic name and location of institution. Descriptive statistics were performed on all variables of interest, 
using SAS 9.4. For centers with responses to both surveys, bivariate analyses were conducted to compare dichotomous responses from 2007 with those from 2017 using chi-square tests and McNemar's tests.

\section{Results}

\section{7 survey}

At the time of the survey, 209 institutions constituted the COG membership and were sent a survey for completion. Investigators from 153 institutions responded (73\%). Of the 2017 reporting institutions, the majority were children's hospitals with an adult medical center affiliation and $27 \%$ were a freestanding children's hospital (Table 1). Approximately half of all institutions reported that their upper age limit for new oncology patients was $<21$ years of age; however, $83 \%$ were able to care for pediatric cancers survivors beyond the age of 21 years.

Of these 153 respondents, 148 (96\%) reported providing late effects care for pediatric cancer survivors. For institutions who stated they provided late effects care for childhood cancer survivors, $96 \%$ reported providing late effects services for central nervous system tumor survivors, and 92\% also cared for survivors after a stem cell transplant. Eligibility criteria for entry into late effects services varied among institutions, with 56\% indicating survivors were eligible for services at 2 years after completion of treatment. Fortyseven percent of institutions saw between 100-500 survivors each year, and $54 \%$ provided survivor appointments between 1 to 3 days per week. Approximately two-thirds of institutions indicated that $<75 \%$ of their eligible patients were seen in a late effects or off-therapy clinic in the prior year.

\section{Survivorship care practices}

Most institutions (88\%) provided a cancer treatment summary to their survivors (Table 2). Models of care regarding survivorship care practices were evaluated in survivors who were $<18$ years of age at their visit, with some institutions reporting these survivors were seen during their regular pediatric oncology clinic by health care professionals staffing clinic $(19 \%)$ or by the treating oncologist and family practice (5\%). Most respondents (75\%) reported that survivors were seen in specialized late effects clinics by designated providers at their pediatric institution. For survivors who required additional risk-based care, most institutions reported referring survivors to a sub-specialists (87\%), while $13 \%$ reported having sub-specialists work within the late effects team. The majority of institutions $(72 \%)$ were able to arrange necessary tests/scans for the same day of the late effects clinic visit.
Psychosocial screening was performed in most late effects clinics and included yearly screening for educational/vocational difficulties (84\%), relationship difficulties (76\%), distress/anxiety/depression (85\%), and risky health behaviors (83\%) (Table 2). Psychosocial screening occurred most frequently during the context of interviews with oncology providers (73\%); $25 \%$ of clinics reported using standardized patient-reported outcomes for psychosocial assessments.

Barriers most often noted for caring for pediatric cancer survivors included lack of dedicated time for late effects program development (58\%), not enough funding for support of program $(41 \%)$, and survivor knowledge deficit about the importance of maintaining cancer-related follow-up (25\%) (Table 3). Seven percent of respondents indicated there were no barriers in caring for pediatric cancer survivors at their institutions.

\section{Comparison of 2007 and 2017 survey results}

There were 121 COG institutions that participated in both surveys, and comparison of responses over this 10-year period is described in Table 4. Of these institutions, more sites offer late effects services for childhood cancer survivors in 2017 compared with 2007 (97\% vs. 92\%, $p<0.001$ ). There were also changes in eligibility criteria for attendance in a late effects clinic with more institutions now designating eligibility at 2 years off treatment (55\% vs. $40 \%$ ) compared with being seen later in their survivorship period. While no differences were noted over this 10 -year period in the number of new pediatric cancer patients seen annually at these institutions, the number of survivor visits increased with approximately $31 \%$ of institutions now seeing $>300$ visits per year, compared with $18 \%$ in 2007 . In addition, the number of days/week when childhood cancer survivors are offered appointments has increased with $31 \%$ of clinics now offering appointments 2-3 days/week compared to $23 \%$ in 2007. Quality of service has also increased, with more survivors now receiving a copy of their cancer treatment summary ( $88 \%$ vs. $67 \%$ in 2007). Barriers to survivor care identified in 2007 were still present in 2017; of note, concerns about both funding and lack of support by program/ other oncologists have increased over this 10 -year period. Perceived survivor knowledge deficit about the importance of maintaining cancer-related follow-up significantly decreased, with only $15 \%$ of institutions perceiving this as one of the top two barriers in 2017 compared with $36 \%$ in 2007.

\section{Non-responding institutions}

To assess potential response bias, non-responding institutions were sent a brief three question survey to assess their involvement in late effects services. This brief survey was 
Table 1 Institutional characteristics and survivorship care at participating COG institutions

\begin{tabular}{|c|c|c|c|}
\hline \multicolumn{2}{|l|}{ Characteristics } & \multirow{2}{*}{$\frac{N}{57}$} & \multirow{2}{*}{$\frac{\%}{37.7}$} \\
\hline Pediatric oncology institution & Children's hospital within adult medical center & & \\
\hline & Freestanding children's hospital & 41 & 27.2 \\
\hline & Children's hospital adjacent to adult medical center & 35 & 23.2 \\
\hline & Community hospital & 7 & 4.6 \\
\hline & Other & 11 & 7.3 \\
\hline \multirow[t]{2}{*}{ Pediatric hematology/oncology fellowship program at institution } & Yes & 74 & 48.7 \\
\hline & No & 78 & 51.3 \\
\hline \multirow{4}{*}{$\begin{array}{l}\text { Upper age limit for newly diagnosed pediatric oncology patients } \\
\text { to begin treatment }\end{array}$} & 18 years & 23 & 15.1 \\
\hline & $>18-21$ years & 58 & 38.2 \\
\hline & $>21-29$ years & 55 & 36.2 \\
\hline & $30+$ years & 16 & 10.5 \\
\hline \multirow{6}{*}{$\begin{array}{l}\text { Average number of new pediatric oncology patients treated annu- } \\
\text { ally }\end{array}$} & Less than 30 new oncology patients/year & 24 & 15.9 \\
\hline & 31-60 new oncology patients/year & 39 & 25.8 \\
\hline & 61-90 new oncology patients/year & 32 & 21.2 \\
\hline & 91-120 new oncology patients/year & 19 & 12.6 \\
\hline & $121-150$ new oncology patients/year & 9 & 6.0 \\
\hline & Greater than 150 new oncology patients/year & 28 & 18.5 \\
\hline \multirow{2}{*}{$\begin{array}{l}\text { Late effects care for childhood cancer survivors provided at } \\
\text { institution }\end{array}$} & Yes & 148 & 96.7 \\
\hline & No & 5 & 3.3 \\
\hline \multirow{5}{*}{$\begin{array}{l}\text { Upper age limit for childhood cancer survivors in long-term } \\
\text { follow-up }\end{array}$} & 18 years & 3 & 2.0 \\
\hline & $>18-21$ years & 16 & 10.5 \\
\hline & $>21-29$ years & 43 & 28.3 \\
\hline & No upper age limit & 83 & 54.6 \\
\hline & Other & 7 & 4.6 \\
\hline \multirow[t]{6}{*}{ Eligibility criteria for entry into LE services } & At least 2 years off treatment & 84 & 56.4 \\
\hline & At least 3 years off treatment & 16 & 10.7 \\
\hline & At least 5 years off treatment & 17 & 11.4 \\
\hline & At least 5 years from diagnosis & 5 & 3.4 \\
\hline & At least $2 / 3$ years off treatment $\& 5$ years from diagnosis & 14 & 9.4 \\
\hline & Other & 13 & 8.7 \\
\hline \multirow[t]{7}{*}{ Number of survivor visits in 2016} & Less than 50 visits & 15 & 10.2 \\
\hline & $50-100$ visits & 24 & 16.3 \\
\hline & $101-300$ visits & 44 & 29.9 \\
\hline & $301-500$ visits & 25 & 17.0 \\
\hline & $501-800$ visits & 11 & 7.5 \\
\hline & Greater than 801 visits & 8 & 5.4 \\
\hline & Data not available & 20 & 13.7 \\
\hline \multirow[t]{6}{*}{ Frequency of childhood cancer survivor appointments offered } & One day/week & 40 & 26.7 \\
\hline & 2-3 days/week & 41 & 27.4 \\
\hline & 4-5 days/week & 26 & 17.3 \\
\hline & One day per month & 11 & 7.3 \\
\hline & Two days per month & 24 & 16.0 \\
\hline & Other & 8 & 5.3 \\
\hline \multirow{4}{*}{$\begin{array}{l}\text { Percentage of pediatric oncology patients eligible for a survivor- } \\
\text { ship visit seen in a late effects clinic in } 2016\end{array}$} & Less than $25 \%$ & 16 & 11.2 \\
\hline & $25-50 \%$ & 24 & 16.8 \\
\hline & $50-75 \%$ & 55 & 38.5 \\
\hline & Greater than $75 \%$ & 48 & 33.5 \\
\hline \multirow{2}{*}{$\begin{array}{l}\text { Program provides clinical consultations to survivors not treated } \\
\text { at institution }\end{array}$} & Yes & 134 & 90.5 \\
\hline & No & 14 & 9.5 \\
\hline
\end{tabular}


Table 1 (continued)

\begin{tabular}{|c|c|c|c|}
\hline Characteristics & & $N$ & $\%$ \\
\hline \multirow[t]{2}{*}{ Patients can self-refer for late effects services } & Self-referral is accepted & 123 & 82.0 \\
\hline & Physician referral is necessary & 27 & 18.0 \\
\hline \multirow[t]{4}{*}{ CNS tumor survivor LE service eligibility } & Yes—seen in general LE clinic & 92 & 61.3 \\
\hline & Yes-seen in specialized neuro-oncology LE clinic & 45 & 30.0 \\
\hline & No & 6 & 4.0 \\
\hline & Other & 7 & 4.7 \\
\hline \multirow{4}{*}{$\begin{array}{l}\text { BMT/stem cell transplant eligibility for LE services (mark all } \\
\text { that apply) }\end{array}$} & Survivors of malignant/oncologic diseases & 135 & 91.2 \\
\hline & Survivors transplanted for benign hematologic disorders & 100 & 67.6 \\
\hline & Survivors transplanted for non-malignant conditions & 90 & 60.8 \\
\hline & N/A (no BMT/stem cell transplant late effects services provided) & 13 & 8.8 \\
\hline
\end{tabular}

values listed do not include missing answers to specific questions

sent to 78 COG investigators, of which 40 responded (51\%). Similar to the overall survey, $95 \%$ reported providing late effects care for pediatric cancer survivors. However, $70 \%$ of brief survey respondents reported being at institutions that treated $<60$ new oncology patients/year (vs. $41 \%$ of 2017 survey respondents), and these institutions were more likely to see survivors in a regular pediatric oncology clinic with health care professionals staffing clinic ( $45 \%$ vs. $19 \%$ of the full 2017 survey respondents).

\section{Discussion}

With an increasing number of childhood cancer survivors at risk for late effects from their cancer and its treatment, survivor-focused care remains a critical dimension in pediatric oncology. Survivor care aims to decrease morbidity and mortality through individualized lifelong surveillance and education to empower survivors. Therefore, the availability of access to survivorship care is critical. The 2007 COG assessment of late effects services provided a wealth of information on the state of survivorship practices, services, and delivery of care. Using this survey as a template, we were able to reassess the state of late effects services in order to determine improvements and continued gaps. The most recent COG survey conducted in 2017 determined that 97\% of responding COG institutions have dedicated care for survivors of childhood cancer, compared with $87 \%$ of those institutions responding in 2007. Improvements also were noted with increased distribution of treatment summaries from $31 \%$ in 2007 to $88 \%$ of institutions now providing a treatment summary during their survivor visit. With research suggesting the impact of long-term follow-up care on survivor's knowledge about their treatment and improvement in surveillance for late effects, this progress seen over the past 10 years will prove instrumental in the overall long-term health of pediatric cancer survivors. [11]
Through comparisons with the prior survey, we were able to demonstrate improvements in the goals that were outlined in the Institute of Medicine report from a provider/clinic perspective [8], including an increase in the number of survivor visits at each institution and the frequency of days that survivor appointments are now offered. These metrics point to the growth of survivor programs, which is promising. However, it is disheartening that there are still survivors who are eligible but are not receiving late effects services. This recent report found that at most institutions less than $75 \%$ of survivors eligible to attend a specialized late effects clinic have actually received this needed survivor care. Previous studies of barriers to care in pediatric-aged survivors have found longer distance from clinic $[12,13]$ and no insurance [14] or public insurance [12] are associated with decreased likelihood of dedicated survivor care. However, additional research is necessary to assess what interventions might be needed from an institutional and provider perspective to overcome obstacles for reaching all survivors. Furthermore, over this 10-year period, perceived health system barriers did not appear to improve, as the lack of dedicated time for late effects program development and funding were identified as the top two identified barriers in both surveys.

Because of the increase in the volume of survivors and continued lack of dedicated time and funding noted in the 2017 survey, the consideration of models of care play an important role in sustaining survivor care capacity in COG clinics. One such model for consideration is the three-level model developed by Wallace et al. using the intensity of treatment received to guide the frequency of follow-up [15-17]. This model has recently been developed into a risk stratification tool for general clinical use, to allow the frequency and type of follow-up care required to vary, thereby better protecting limited resources in specialized pediatric late effects clinics. In addition, a shared care model in which childhood cancer survivors receive late effects care through a collaboration of both late effects specialty-care and primary 
Table 2 Survivorship care practices at participating COG institutions

\begin{tabular}{|c|c|c|c|}
\hline Long-term follow-up service & & $N$ & $\%$ \\
\hline Clinic provides survivors with a copy of their cancer treatment & Yes & 133 & 88.1 \\
\hline summary & No & 18 & 11.9 \\
\hline Models of care used to follow late effects (for survivors $<18$ ) & $\begin{array}{l}\text { In specialized LE program by designated providers in pediatric } \\
\text { institution }\end{array}$ & 108 & 74.5 \\
\hline & $\begin{array}{l}\text { In regular pediatric oncology clinic by health care professionals } \\
\text { staffing clinic }\end{array}$ & 28 & 19.3 \\
\hline & $\begin{array}{l}\text { In regular pediatric oncology clinic by treating oncologist and } \\
\text { family practice }\end{array}$ & 7 & 4.8 \\
\hline & No specialized LE follow-up provided & 2 & 1.4 \\
\hline Models of care used to manage risk-based surveillance (for & Designated LE clinic team refers to sub-specialists & 88 & 59.1 \\
\hline survivors < 18) & Treating oncologist manages LE care and refers to sub-specialists & 42 & 28.2 \\
\hline & $\begin{array}{l}\text { Designated LE clinic staffed by LE team and sub-specialists } \\
\text { together }\end{array}$ & 19 & 12.7 \\
\hline Timing of risk-based surveillance ( $<18$ only) & $\begin{array}{l}\text { Necessary tests/scans most often arranged for same day of LE } \\
\text { visit }\end{array}$ & 108 & 72.5 \\
\hline & $\begin{array}{l}\text { Necessary surveillance scans/tests most often done on another } \\
\text { day/time from LE clinic visit }\end{array}$ & 41 & 27.5 \\
\hline Clinic provides yearly screening for adverse educational and/or & Yes & 119 & 84.4 \\
\hline vocational progress & No & 14 & 9.9 \\
\hline & Only once-no yearly follow-up & 6 & 4.3 \\
\hline & N/A & 2 & 1.4 \\
\hline Clinic provides yearly screening for relationship difficulties & Yes & 107 & 75.9 \\
\hline & No & 25 & 17.7 \\
\hline & Only once-no yearly follow-up & 7 & 5.0 \\
\hline & N/A & 2 & 1.4 \\
\hline Clinic provides yearly screening for distress, anxiety, and depres- & Yes & 120 & 85.1 \\
\hline sion & No & 12 & 8.5 \\
\hline & Only once-no yearly follow-up & 7 & 5.0 \\
\hline & N/A & 2 & 1.4 \\
\hline Clinic provides yearly screening for risky health behaviors & Yes & 116 & 83.4 \\
\hline & No & 14 & 10.1 \\
\hline & Only once-no yearly follow-up & 6 & 4.3 \\
\hline & N/A & 3 & 2.2 \\
\hline Method(s) of psychosocial screening used in long-term follow-up & Standardized patient-reported outcome assessment tools & 32 & 25.2 \\
\hline clinic (mark all that apply) & Review of systems or needs checklist & 59 & 46.5 \\
\hline & Interview with oncology provider & 93 & 73.2 \\
\hline & Interview with psychologist/neuropsychologist & 46 & 36.2 \\
\hline & $\begin{array}{l}\text { Interview with social work/professional counselor/educational } \\
\text { liaison }\end{array}$ & 80 & 63.0 \\
\hline & Interview with nurse & 3 & 2.4 \\
\hline
\end{tabular}

care providers may need to be considered as a solution for meeting the increased needs of pediatric cancer survivors [18-21]. Research to implement and evaluate these different models should be considered to improve survivor's return to cancer follow-up care. Future research also needs to consider challenges of transitioning survivors of childhood cancer from pediatric to adult care since $45 \%$ of COG institutions have an upper age limit seeing childhood cancer survivors for long-term follow-up care.
Barriers to survivorship care at the patient/family level have been most frequently assessed to date; however, limited data are available on barriers to care at the provider and health system levels [22]. The most commonly identified provider barriers in the literature include lack of knowledge/ comfort regarding follow-up care guidelines and/or recommended care, options for childhood cancer survivors transitioning from pediatric to adult care, adequate resources to deliver survivor care, availability of specialized services due 
Table 3 Provider perception of barriers to pediatric cancer survivorship care

\begin{tabular}{|c|c|c|c|}
\hline Barriers & & $N$ & $\%$ \\
\hline \multirow{7}{*}{$\begin{array}{l}\text { Problematic barriers in caring for pediatric cancer survivors (top } 2 \\
\text { responses) }\end{array}$} & Lack of dedicated time for late effects program development & 79 & 57.7 \\
\hline & Not enough funding for support of program & 56 & 40.9 \\
\hline & Survivor lack of health care insurance or insurance limitations & 34 & 24.8 \\
\hline & $\begin{array}{l}\text { Survivor knowledge deficit about the importance of maintain- } \\
\text { ing cancer-related follow-up }\end{array}$ & 25 & 18.3 \\
\hline & $\begin{array}{l}\text { Lack of perceived need or support for LE services/program by } \\
\text { other oncologists }\end{array}$ & 18 & 13.1 \\
\hline & Lack of survivor desire to be followed by the LE team & 17 & 12.4 \\
\hline & There are no barriers in my institution & 10 & 7.3 \\
\hline
\end{tabular}

to geographic obstacles, insurance coverage or reimbursement for complex services provided, and adequate in-network providers and specialists required to address long-term health outcomes [22]. Our findings mirror the documented concerns with the addition of lack of funding for the support of the late effects program. Future research studies utilizing dissemination and implementation intervention strategies would aid in our understanding of, and how best to overcome some of these barriers.

Another barrier to survivor care to be addressed is the lack of perceived need or support for late effects services from other pediatric oncologists. While this barrier was only reported by $13 \%$ of overall respondents, it increased from 11 to $17 \%$ among respondents of both the 2007 and 2017 surveys. Support from other oncologists for dedicated late effects care is crucial as survivors often depend on the opinion of their treating oncologist when deciding upon future care. A survey of pediatric oncologists found that $38 \%$ of oncologists prefer to follow long-term survivors as long as possible rather than referring to another physician; however, this same study revealed that only $33 \%$ of respondents could correctly choose the appropriate long-term follow-up based on COG LTFU guidelines for three clinical vignettes [23]. This finding highlights the need for continued education for pediatric oncologists regarding survivor care. Yet, in a national survey, nearly $50 \%$ of survivorship clinic directors and fellowship program directors reported a lack of time for trainees to learn about late effects [24]. Formal fellowship training and didactic lectures regarding the importance of survivorship care are needed to improve support for late effects services among pediatric oncologists. Additionally, research into the timing of how to best integrate survivorship care with general oncology care is warranted. It is important to note that when comparing responses regarding barriers to fellow survivorship education, the survivorship clinic directors reported greater lack of fellow interest in survivorship than training program directors [24]. This difference in perception is important to highlight since the 2007 and 2017 COG surveys may have been completed by different respondents. With the growth of survivor programs, it is possible that more survivor-focused personnel, who are more likely to report lack of support, completed the 2017 survey. Survivor clinicians and treating oncologists must work together in the promotion of long-term survivorship care to improve survivor compliance to surveillance recommendations.

While this study provides a comprehensive view of the state of survivorship care within COG institutions, there are several limitations that need to be considered. First, only $73 \%$ of institutions responded to the full survey. This could be due to in part to the contact list of COG survivor providers not being current or contacted providers not receiving or opening the survey due to institutional email firewalls and the high volume of spam received. Responding providers also noted a lack of time and resources which may have played a role in non-respondents. To take into consideration those who did not complete the survey, we were able to contact an additional 40 providers using email with an imbedded smaller survey that was easier to complete. This provided us with a more accurate count of institutions that now support late effects care. Because the overall number of institutions delivering late effects care from the 2007 survey was $87 \%$ (less than the $92 \%$ in those who were able to be matched with 2017 survey results), we acknowledge that these results may overestimate the late effects care currently provided and their emphasis of the importance of survivor care. Furthermore, the definition of late effects care varies between institutions and is not limited to dedicated care with a survivor specialist which may lead to differential care delivery among institutions. Finally, it is important to note that this survey was distributed in 2017 prior to the COVID-19 pandemic; therefore, the impact of the pandemic on survivorship care is not reflected in the responses.

This overview provides insight into the contemporary provision of survivorship care throughout COG institutions. It also highlights the importance of research towards more efficient strategies to ensure all survivors have the opportunity to receive appropriate and equitable care. Pending 
Table 4 Comparison of 121 institutions that provided responses from 2007 to 2017 survey

\begin{tabular}{|c|c|c|c|c|c|c|}
\hline Long-term follow-up service & & $2007 \mathrm{~N}$ & $\%$ & $2017 \mathrm{~N}$ & $\%$ & $p$-value* \\
\hline Late effects care for childhood cancer survivors & Yes & 111 & 91.7 & 117 & 96.7 & \\
\hline provided at institution & No & 10 & 8.3 & 4 & 3.3 & $<.0001$ \\
\hline Does your program provide clinical consultations & Yes & 96 & 86.5 & 108 & 92.3 & 0.004 \\
\hline & No & 15 & & 9 & 7.7 & \\
\hline Can patients self-refer for late effects services at & Yes & 89 & 80.2 & 98 & 82.4 & $<.0001$ \\
\hline & No & 22 & 19.8 & 21 & 17.6 & \\
\hline Eligibility criteria for entry into LE services & at least 2 years off treatment & 44 & 40.4 & 65 & 55.1 & \\
\hline & at least 3 years off treatment & 22 & 20.2 & 28 & 23.7 & \\
\hline & at least 5 years off treatment & 8 & 7.3 & 5 & 4.2 & \\
\hline & at least 5 years from diagnosis & 15 & 13.8 & 10 & 8.5 & \\
\hline & Other/no defined criteria & 20 & 18.3 & 10 & 8.5 & \\
\hline Average number of new pediatric oncology & Less than 30 new oncology patients/year & 16 & 15.0 & 14 & 11.6 & \\
\hline patients treated annually & 31-60 new oncology patients/year & 31 & 29.0 & 30 & 25.0 & \\
\hline & 61-90 new oncology patients/year & 26 & 24.3 & 29 & 24.2 & \\
\hline & 91-120 new oncology patients/year & 9 & 8.4 & 17 & 14.2 & \\
\hline & $121-150$ new oncology patients/year & 10 & 9.3 & 6 & 5.0 & \\
\hline & Greater than 150 new oncology patients/year & 15 & 14.0 & 24 & 20.0 & \\
\hline Number of survivor visits in 2016 & Less than 50 visits & 4 & 3.8 & 12 & 10.3 & \\
\hline & $50-100$ visits & 29 & 27.1 & 17 & 14.7 & \\
\hline & $101-300$ visits & 44 & 41.1 & 33 & 28.5 & \\
\hline & $301-500$ visits & 12 & 11.2 & 18 & 15.5 & \\
\hline & $501-800$ visits & 4 & 3.7 & 10 & 8.6 & \\
\hline & Greater than 801 visits & 3 & 2.8 & 8 & 6.9 & \\
\hline & Data not available & 11 & 10.3 & 18 & 15.5 & \\
\hline Frequency of childhood cancer survivor appoint- & one day/week & 34 & 30.9 & 29 & 24.4 & \\
\hline ments offered & 2-3 days/week & 25 & 22.7 & 37 & 31.1 & \\
\hline & 4-5 days/week & 13 & 11.8 & 19 & 16.0 & \\
\hline & one day per month & 9 & 8.2 & 10 & 8.4 & \\
\hline & two days per month & 19 & 17.3 & 18 & 15.1 & \\
\hline & Other & 10 & 9.1 & 6 & 5.0 & \\
\hline Do all/almost all survivors receive a copy of their & Yes & 72 & 67.3 & 106 & 88.3 & \\
\hline cancer treatment summary? & No & 35 & 32.7 & 14 & 11.7 & $<.0001$ \\
\hline $\begin{array}{l}2 \text { most problematic barriers in caring for pediatric } \\
\text { cancer survivors }\end{array}$ & $\begin{array}{l}\text { Lack of dedicated time for late effects program } \\
\text { development }\end{array}$ & 55 & 51.9 & 62 & 58.5 & \\
\hline & Not enough funding for support of program & 38 & 35.9 & 48 & 45.3 & \\
\hline & $\begin{array}{l}\text { Survivor knowledge deficit about the importance } \\
\text { of maintaining cancer-related follow-up }\end{array}$ & 38 & 35.9 & 16 & 15.1 & \\
\hline & $\begin{array}{l}\text { Survivor lack of health care insurance or insurance } \\
\text { limitations }\end{array}$ & 23 & 21.7 & 28 & 26.4 & \\
\hline & $\begin{array}{l}\text { Lack of survivor desire to be followed by the LE } \\
\text { team }\end{array}$ & 14 & 13.2 & 12 & 11.3 & \\
\hline & $\begin{array}{l}\text { Lack of perceived need or support for LE services/ } \\
\text { program by other oncologists }\end{array}$ & 12 & 11.3 & 18 & 17.0 & \\
\hline & There are no barriers in my institution & 7 & 6.6 & 5 & 4.7 & \\
\hline & Other & 9 & 8.5 & 13 & 12.3 & \\
\hline
\end{tabular}

*McNemar test for dichotomous comparison of changes in answers from 2007 to 2017 
planned analyses of this survey will provide assessments of workforce resources, as well as transition of care. Future survey administration could examine other preventive health behaviors recommended, impacts of survivorship care plans offered through survivorship care, and utilization of telemedicine for follow-up cancer care visits since its use was expanded during the COVID-19 pandemic. Additional research is required to determine the impact of attendance in a survivorship clinic on the physical health and psychosocial outcomes in cancer survivors. Promising results could lead to increased resources and decreased provider and systemlevel barriers.

\section{Scientific impact}

Delivery of care plans and management of late effects are priorities for quality survivorship care as recommended by the Institute of Medicine. This survey provides a snapshot of the status of late effects services within COG institutions and highlights improvements that have been made within COG institutions to reach Institute of Medicine goals. In addition, it provides information on residual gaps in services and informs the future design of integrated and comprehensive models that can more fully meet the needs of all pediatric cancer survivors.

Author contribution All authors contributed to the study conception and design. Material preparation, data collection, and analysis were performed by K.E. Effinger, R. Haardörfer, J. Gilleland Marchak, C. Escoffery, W. Landier, A. Kommajosula, E. Hendershot, K.T. Sadak, D. Eshelman-Kent, K. Kinahan, D.R. Freyer, E.J. Chow, and A.C. Mertens. The first draft of the manuscript was written by K.E. Effinger, J. Gilleland Marchak, C. Escoffery, R. Haardörfer, and A.C. Mertens, and all authors commented on previous versions of the manuscript. All authors read and approved the final manuscript.

Funding This work was supported by the Children's Oncology Group Outcomes and Survivorship, Adolescent and Young Adult, and Nursing Committees, the National Cancer Institute under Award Numbers U10CA180886 and UG1CA189955, the National Cancer Institute under Award Number CA218389-04, and the Intervention Development, Dissemination and Implementation Developing shared resource of Winship Cancer Institute of Emory University and NIH/NCI under award number P30CA138292.

\section{Declarations}

Ethical approval The Emory Institutional Review Board (IRB) deemed this study exempt from IRB review.

Competing interests The authors declare no competing interests.

Disclaimer The content is solely the responsibility of the authors and does not necessarily represent the official views of the National Institutes of Health.

\section{References}

1. Howlader N, Noone AM, Krapcho M, et al. SEER Cancer Statistics Review, 1975-2018. Bethesda, MD: National Cancer Institute. https://seer.cancer.gov/csr/1975_2018/, based on November 2020 SEER data submission, posted to the SEER website, April 2021.

2. Oeffinger KC, Mertens AC, Sklar CA, Kawashima T, Hudson MM, Meadows AT, Friedman DL, Marina N, Hobbie W, Kadan-Lottick NS, Schwartz CL, Leisenring W, Robison LL. Childhood Cancer Survivor Study. Chronic health conditions in adult survivors of childhood cancer. N Engl J Med. 2006;355(15):1572-82. https://doi.org/10.1056/NEJMsa0601 85.

3. Hudson MM, Ness KK, Gurney JG, Mulrooney DA, Chemaitilly W, Krull KR, Green DM, Armstrong GT, Nottage KA, Jones KE, Sklar CA, Srivastava DK, Robison LL. Clinical ascertainment of health outcomes among adults treated for childhood cancer. JAMA. 2013;309(22):2371-81. https://doi.org/10.1001/ jama.2013.6296.Erratum.In:JAMA.2013Jul3;310(1):99.

4. Mertens AC, Liu Q, Neglia JP, Wasilewski K, Leisenring W, Armstrong GT, Robison LL, Yasui Y. Cause-specific late mortality among 5-year survivors of childhood cancer: the Childhood Cancer Survivor Study. J Natl Cancer Inst. 2008;100(19):1368-79. https://doi.org/10.1093/jnci/djn310.

5. Armstrong GT, Kawashima T, Leisenring W, Stratton K, Stovall M, Hudson MM, Sklar CA, Robison LL, Oeffinger KC. Aging and risk of severe, disabling, life-threatening, and fatal events in the childhood cancer survivor study. J Clin Oncol. 2014;32(12):1218-27. https://doi.org/10.1200/JCO.2013.51. 1055.

6. Children's Oncology Group. Long-Term Follow-Up Guidelines for Survivors of Childhood, Adolescent, and Young Adult Cancers. 2018. Available from: http://survivorshipguidelines.org/

7. Landier W, Bhatia S, Eshelman DA, Forte KJ, Sweeney T, Hester AL, Darling J, Armstrong FD, Blatt J, Constine LS, Freeman CR, Friedman DL, Green DM, Marina N, Meadows AT, Neglia JP, Oeffinger KC, Robison LL, Ruccione KS, Sklar CA, Hudson MM. Development of risk-based guidelines for pediatric cancer survivors: the Children's Oncology Group Long-Term Follow-Up Guidelines from the Children's Oncology Group Late Effects Committee and Nursing Discipline. J Clin Oncol. 2004;22(24):4979-90. https://doi.org/10.1200/JCO.2004.11.032.

8. Institute of Medicine, National Research Council National Cancer Policy Board. Childhood cancer survivorship: improving care and quality of life. Washington (DC): National Academies Press, 2003.

9. Eshelman-Kent D, Kinahan KE, Hobbie W, Landier W, Teal S, Friedman D, Nagarajan R, Freyer DR. Cancer survivorship practices, services, and delivery: a report from the Children's Oncology Group (COG) nursing discipline, adolescent/young adult, and late effects committees. J Cancer Surviv. 2011;5(4):345-57. https://doi.org/10.1007/s11764-011-0192-8.

10. Ross JA, Severson RK, Pollock BH, Robison LL. Childhood cancer in the United States: a geographical analysis of cases from the pediatric cooperative clinical trials groups. Cancer. 1996;77:201-7. https://doi.org/10.1002/(SICI)1097-0142(19960 101)77:1\%3c201::AID-CNCR32\%3e3.0.CO;2-7.Cancer.

11. Signorelli C, Wakefield CE, Fardell JE, Wallace W, Robertson EG, McLoone JK, Cohn RJ. The impact of long-term follow-up care for childhood cancer survivors: a systematic review. Crit Rev Oncol Hematol. 2017;114:131-8. https://doi.org/10.1016/j. critrevonc.2017.04.007.

12. Daly A, Williamson Lewis R, Vangile K, Wasilewski Masker K, Effinger KE, Meacham LR, Mertens AC. Survivor clinic 
attendance among pediatric- and adolescent-aged survivors of childhood cancer. J Cancer Surviv. 2019;13(1):56-65. https:// doi.org/10.1007/s11764-018-0727-3.

13. Barakat LP, Schwartz LA, Szabo MM, Hussey HM, Bunin GR. Factors that contribute to post-treatment follow-up care for survivors of childhood cancer. J Cancer Surviv. 2012;6(2):155-62. https://doi.org/10.1007/s11764-011-0206-6.

14. Zheng DJ, Sint K, Mitchell HR, Kadan-Lottick NS. Patterns and predictors of survivorship clinic attendance in a population-based sample of pediatric and young adult childhood cancer survivors. J Cancer Surviv. 2016;10(3):505-13. https://doi.org/10.1007/ s11764-015-0493-4.

15. Wallace WH, Blacklay A, Eiser C, Davies H, Hawkins M, Levitt GA, Jenney ME. Late Effects Committee of the United Kingdom Children's Cancer Study Group (UKCCSG). Developing strategies for long term follow up of survivors of childhood cancer. BMJ. 2001;323(7307):271-4. https://doi.org/10.1136/bmj.323. 7307.271.

16. Eiser C, Absolom K, Greenfield D, Glaser A, Horne B, Waite $\mathrm{H}$, Urquhart T, Wallace WH, Ross R, Davies H. Follow-up after childhood cancer: evaluation of a three-level model. Eur J Cancer. 2006;42(18):3186-90. https://doi.org/10.1016/j.ejca.2006.08.001.

17. Frobisher C, Glaser A, Levitt GA, Cutter DJ, Winter DL, Lancashire ER, Oeffinger KC, Guha J, Kelly J, Reulen RC, Hawkins MM. Risk stratification of childhood cancer survivors necessary for evidence-based clinical long-term follow-up. Br J Cancer. 2017;117(11):1723-31. https://doi.org/10.1038/bjc.2017.347.

18. Shad A, Myers SN, Hennessy K. Late effects in cancer survivors: "the shared care model." Curr Oncol Rep. 2012;14(2):182-90. https://doi.org/10.1007/s11912-012-0224-1.

19. Hall SJ, Samuel LM, Murchie P. Toward shared care for people with cancer: developing the model with patients and GPs. Fam Pract. 2011;28(5):554-64. https://doi.org/10.1093/fampra/ cmr012.
20. Oeffinger KC, McCabe MS. Models for delivering survivorship care. J Clin Oncol. 2006;24(32):5117-24. https://doi.org/10.1200/ JCO.2006.07.0474.

21. Hudson MM, Bhatia S, Casillas J, et al. Long-term follow-up care for childhood, adolescent, and young adult cancer survivors. Pediatrics. 2021;148(3):e2021053127.

22. Mobley EM, Moke DJ, Milam J, Ochoa CY, Stal J, Osazuwa N, Bolshakova M, Kemp J, Dinalo JE, Motala A, Baluyot D, Hempel S. Disparities and barriers to pediatric cancer survivorship care . Technical Brief No. 39. (Prepared by the Southern California Evidence-based Practice Center under Contract No. 75Q80120D00009.) Rockville, MD: Agency for Healthcare Research and Quality; March 2021. https://doi.org/10.23970/ AHRQEPCTB39. Posted final reports are located on the Effective Health Care Program search page.

23. Henderson TO, Hlubocky FJ, Wroblewski KE, Diller L, Daugherty CK. Physician preferences and knowledge gaps regarding the care of childhood cancer survivors: a mailed survey of pediatric oncologists. J Clin Oncol. 2010;28(5):878-83. https://doi.org/10. 1200/JCO.2009.25.6107.

24. Nathan PC, Schiffman JD, Huang S, Landier W, Bhatia S, Eshelman-Kent D, Wright J, Oeffinger KC, Hudson MM. Childhood cancer survivorship educational resources in North American pediatric hematology/oncology fellowship training programs: a survey study. Pediatr Blood Cancer. 2011;57(7):1186-90. https:// doi.org/10.1002/pbc.23214.

Publisher's note Springer Nature remains neutral with regard to jurisdictional claims in published maps and institutional affiliations. 